\title{
Synthesis and Characterization of Polymer-Metal Chelates Derived from Poly(4-methacryloxy acetophenone)-Methyl Methacrylate Isonicotinoyl Hydrazone Resins
}

\author{
K. KESAVULU, T. RAVI SANKAR and P. VENKATA RAMANA* \\ Department of Chemistry, Sri Krishnadevaraya University, Anantapur - 515 003, India \\ ramanapv2103@yahoo.com
}

Received 18 February 2013 / Accepted 19 March 2013

\begin{abstract}
Copolymers of 4-methacryloxyacetophenone with methyl methacrylate were prepared in ethyl methyl ketone using benzoyl peroxide as the initiator at $70{ }^{\circ} \mathrm{C}$. They were characterized by elemental analysis, Fourier transform infrared, ${ }^{1} \mathrm{H} \mathrm{NMR},{ }^{13} \mathrm{C} \mathrm{NMR}$ and scanning electron microscopy. $\mathrm{Cu}$ (II) and $\mathrm{Ni}$ (II) chelates of the functionalized copolymer were prepared and characterized by elemental analysis, Fourier transform infrared, scanning electron microscopy and EPR spectra. Thermogravimetric analysis of polymers and metal chelates were performed.
\end{abstract}

Keywords: Polymer-metal chelates, Copper(II) and Nickel(II) complexes, Cross-linking agent, chemical modification, EPR, Scanning electron microscope

\section{Introduction}

The synthesis of polymers containing reactive functional groups has been an active field of research in polymer science. It provides an approach to a subsequent modification of the polymer for the required application. The synthesis and properties of polymers having chelating ligands ${ }^{1-3}$ have been reported. Polymer-bound chelating ligands including polydentate amines, crown ethers, schiff bases and porphyrins have been described ${ }^{4-6}$. A survey of the literature also reveals that hydrazones derived from low molecular weight aromatic carbonyl compounds draw the attention of synthetic chemists due to their varied biological activities ${ }^{7,8}$. Hydrazones also find their application in analytical chemistry. They act as multidentate ligands with metals forming colored chelates. These chelates are then used in selective and sensitive determination of metal ions ${ }^{9-12}$. With a view to the complexing abilities of hydrazone derivatives of acetophenone incorporated into the polymer, the 4-methacryloxy acetophenone (MAP) cross-linked with methyl methacrylate (MMA) was selected. The isonicotinoyl hydrazone (INH) derivative of the cross-linked copolymer acts as polymeric ligand towards metal ions. We report herein the synthesis and characterization of hydrazone derivatives of poly MAP-MMA copolymer towards $\mathrm{Cu}$ (II) and $\mathrm{Ni}(\mathrm{II})$ ions. 


\section{Experimental}

To $0.2 \mathrm{~mol}$ 4-hydroxy acetophenone in ethyl methyl ketone, $0.2 \mathrm{~mol}$ triethylamine (TEA) was added with stirring at $0-5{ }^{\circ} \mathrm{C}$. To this mixture $0.2 \mathrm{~mol}$ methacroyl chloride in ether was added drop wise over $45 \mathrm{~min}$. Stirring was continued for $1 \mathrm{~h}$. The precipitate that resulted was filtered and washed thrice with ether. The ethereal layer was evaporated to obtain 4-methacryloxy acetophenone (MAP) monomer.

Methyl methacrylate (MMA) was freed from the inhibitor and distilled under vacuum. Benzoyl peroxide (BPO) was recrystallized form chloroform-methanol (1:1) mixture and the solvents were purified by distillation.

\section{Polymerization}

Poly(MAP-MMA) was prepared in ethyl methyl ketone using BPO as the free radical initiator at $70{ }^{\circ} \mathrm{C}$. The monomer concentration was $5 \mathrm{M}$ and that of the initiator was 0.25 wt $\%$ based on the monomers, MAP and MMA. Appropriate amounts of monomers, initiator and solvent were mixed in a polymerization tube, degassed, sealed and kept at $70{ }^{\circ} \mathrm{C}$ in a thermostatic water bath for $18 \mathrm{~h}$. The copolymer was precipitated in methanol, purified by at least two reprecipitations by methanol from chloroform solution and dried in vacuum at $60{ }^{\circ} \mathrm{C}$.

\section{Functionalization of polymer}

Functionalization of copoly(MAP-MMA) was achieved by incorporating a isonicotinoyl hydrazone moiety through a post polymerization reaction. Cross-linked polymer $(5 \mathrm{~g})$, Isonicotinic acid hydrazine (INH) $(10 \mathrm{~g})$ and sodium acetate $(6.8 \mathrm{~g})$ in dimethylformamidewater $\left(\mathrm{DMF}-\mathrm{H}_{2} \mathrm{O}\right)$ mixture $(1: 1)$ were placed in a $500 \mathrm{~mL}$ round-bottomed flask and refluxed for $12 \mathrm{~h}$. The addition of excess of methanol to the reaction mixture results in the precipitation of the polymer. The contents were filtered, the functionalized polymer (MAPMMA-INH) was collected, washed with water and dried.

\section{Polymer-metal chelates}

The polychelates were prepared by reacting a DMF solution of functionalized polymer $(5 \mathrm{~g})$ and an aqueous solution of $\mathrm{CuCl}_{2} \cdot 2 \mathrm{H}_{2} \mathrm{O}, \mathrm{NiCl}_{2} \cdot 6 \mathrm{H}_{2} \mathrm{O}(5 \mathrm{~g})$ after adjusting the $\mathrm{pH}$ to 7 with ammonia. The reaction mixture was refluxed for $10 \mathrm{~h}$. and the resulting solid polychelate was washed with hot water followed by ethanol and dried under vacuum. The reaction of 2-hydroxy acetophenone with methacryl chloride, its copolymerization with MMA and the final conversion to the hydrazone functionality are presented in Scheme 1.

\section{Measurements}

Infrared spectra were recorded with a Perkin-Elmer spectrophotometer 983-G using $\mathrm{KBr}$ pellets and FT-IR spectra of the cross-linked copolymers and their meal chelates were recorded on Digilab FT IR-Win-IR Pro using $\mathrm{KBr}$ pellets. ${ }^{1} \mathrm{H}-\mathrm{NMR}$ spectra were run on a Bruker CXP $90 \mathrm{MHz}$ spectrometer $\mathrm{CDCl}_{3}$ solution with TMS as internal standard. Proton decoupled ${ }^{13} \mathrm{C}$ NMR spectra were recorded on a Bruker CXP 90 operating at $22.6 \mathrm{MHz}$ spectrometer in $\mathrm{CDCl}_{3}$. Tetramethylsilane (TMS) was the internal standard. Thermogravimetric analysis was carried out on a Perkin Elmer model 3700 with TGA 7 computer and Mettler TA 3000 thermal analyzer in air. Thermograms were recorded with $10 \mathrm{mg}$ samples at a heating rate of $10{ }^{\circ} \mathrm{C} \mathrm{min}^{-1}$. EPR spectra of the polymer metal chelates were recorded on a JEOL-FA 200 spectrometer at $303 \mathrm{~K}$. Elemental analysis was carried out with Thermo Finnigan FLASH EA 1112 CHNS analyzer. Scanning electron micrographs were taken on JSM-840A Jeol-Japan. The copolymer was coated with gold. 


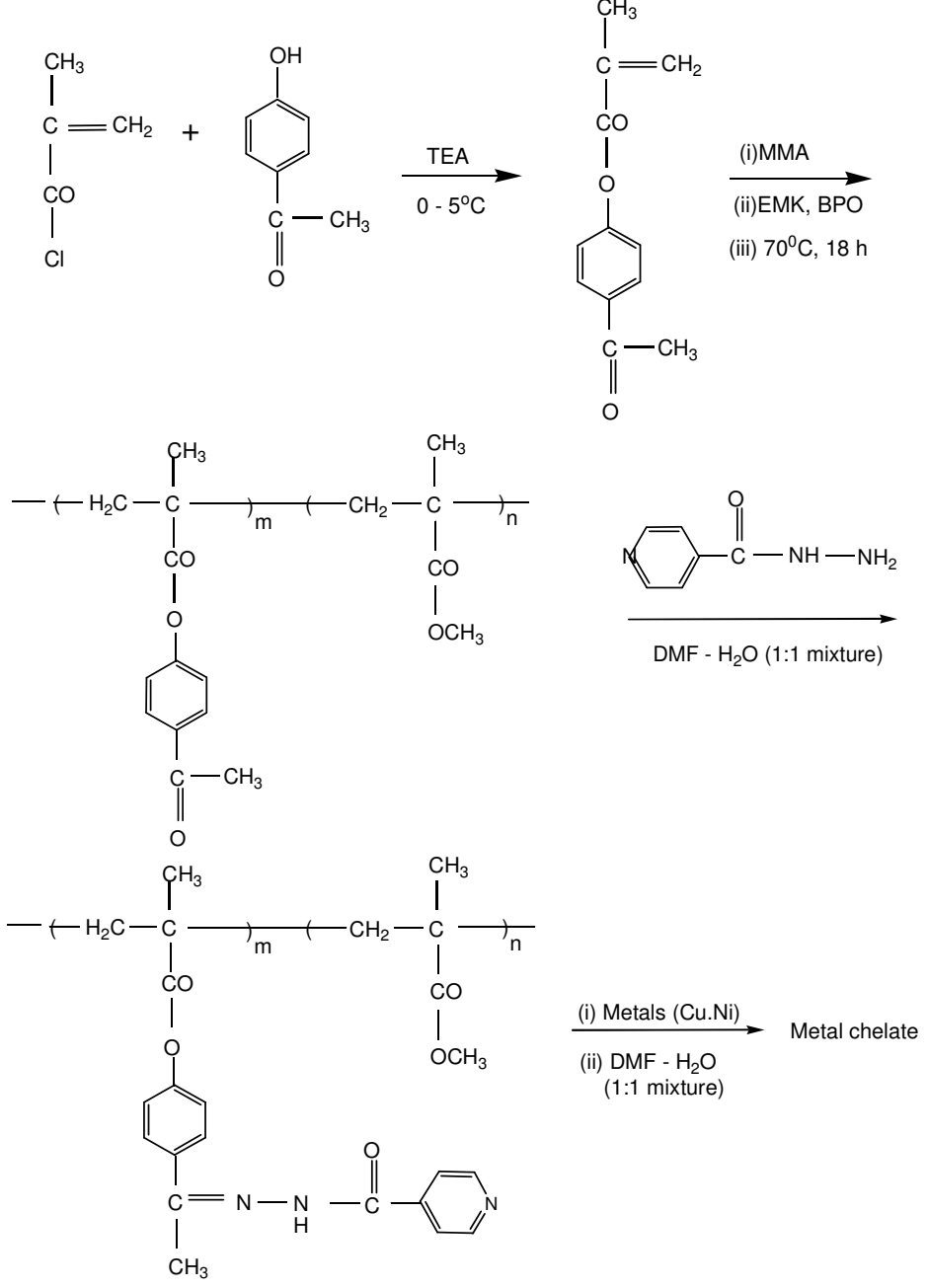

Scheme 1

\section{Results and Discussion}

\section{Characterization of the monomer}

\section{IR spectra}

The IR spectrum of MAP monomer shows an absorption band at $2977 \mathrm{~cm}^{-1}$ due to $\mathrm{CH}$ stretching vibrations in alkane. The ester carbonyl of MAP appeared at $1718 \mathrm{~cm}^{-1}$. The presence of absorption band at $1414 \mathrm{~cm}^{-1}$ is attributed to the $\mathrm{C}=\mathrm{C}$ skeletal vibration of phenyl ring. The C-O-C stretching vibrations are noticed at $1131 \mathrm{~cm}^{-1}$.

\section{${ }^{1} H N M R$}

The ${ }^{1} \mathrm{H}-\mathrm{NMR}$ of MAP shows two singlets at $\delta 2.1$ and $2.5 \mathrm{ppm}$ corresponding to methacryloyl and keto methyl protons respectively. Two signals at $\delta$ value 5.9 and $6.5 \mathrm{ppm}$ correspond to vinyl protons. The signals at $\delta 7.0$ and $8.2 \mathrm{ppm}$ arise from the protons of disubstituted phenyl ring. 


\section{Characterization of the copolymer}

\section{Elemental analysis}

Elemental analysis data are presented in Table 1. The data show that the conversion of carbonyl groups to hydrazone function was $41 \%$ by weight.

Table 1. Elemental analysis of MAP-MMA copolymer, isonicotinoyl hydrazone functionalized polymer and metal chelates

\begin{tabular}{ccccc}
\hline \multirow{2}{*}{ Element } & \multicolumn{3}{c}{ Found, \% } \\
\cline { 2 - 5 } & MAP- & MAP-MMA- & MAP-MMA-INH- & $\begin{array}{c}\text { MAP-MMA- } \\
\text { INH-Ni(II) }\end{array}$ \\
& MMA & INH & Cu(II) & 52.58 \\
$\mathrm{C}$ & 68.94 & 62.74 & 52.29 & 4.67 \\
$\mathrm{H}$ & 5.98 & 5.71 & 4.86 & 2.47 \\
$\mathrm{~N}$ & - & 4.72 & 2.53 & - \\
$\mathrm{Cu}(\mathrm{II})$ & - & - & 1.47 & 1.58 \\
$\mathrm{Ni}(\mathrm{II})$ & - & - & - & \\
& & $41^{*}$ & & \\
\hline
\end{tabular}

\section{IR spectra}

${ }^{*}$ Indicates the percentage of conversion

The IR spectrum of copoly(MAP-MMA) is shown in Figure 1. The IR spectrum shows bands at 3010 and $2929 \mathrm{~cm}^{-1}$ because of aromatic $\mathrm{CH}$ and back bone methylene stretching vibrations respectively. The absorption band at $1737 \mathrm{~cm}^{-1}$ corresponds to the ester carbonyl group. The ketonic functionality is identified by a sharp absorption ${ }^{13-15}$ band around $1690 \mathrm{~cm}^{-1}$.

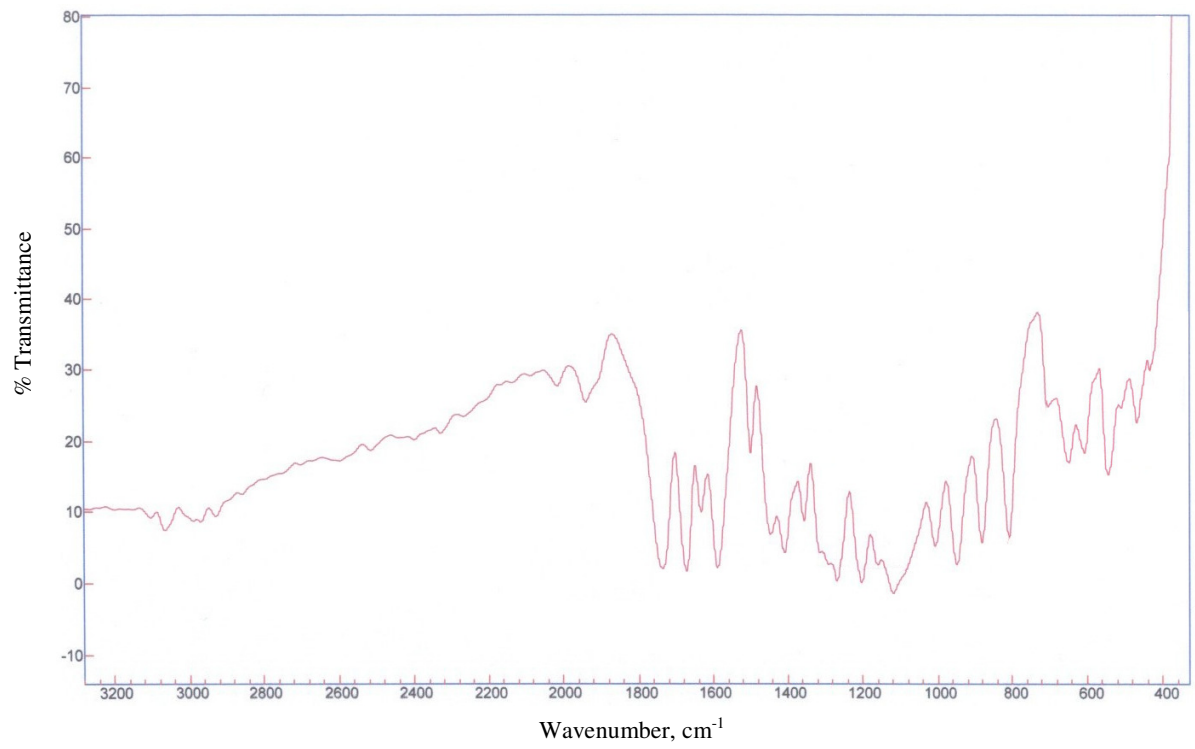

Figure 1. FT-IR spectrum of MAP-MMA copolymer

\section{${ }^{1}$ H NMR spectra}

The NMR study helps in the confirmation of copolymer formation. ${ }^{1} \mathrm{H}$ NMR spectrum of copoly(MAP-MMA) shows a signal at $\delta$ value 1.3 is due to backbone methyl $\left(\mathrm{CH}_{3}\right)$ protons. The signals at $\delta 2.1$ and $2.2 \mathrm{ppm}$ arise from the backbone methylene $\left(-\mathrm{CH}_{2}\right)$ protons. The signal 
at $\delta$ value $2.5 \mathrm{ppm}$ corresponds to methyl protons of $-\mathrm{CO}-\mathrm{CH}_{3}$. The resonance signal at $\delta$ $3.6 \mathrm{ppm}$ is due to the $-\mathrm{OCH}_{3}$ protons of MMA unit. The multiplet between $\delta$ value 7.2-8.2 ppm correspond to the protons of disubstituted phenyl ring.

\section{${ }^{13}$ C NMR spectra}

The ${ }^{13} \mathrm{C}$ NMR spectrum of MAP-MMA cross-linked copolymer is shown in Figure 2. The resonance signal at $48.3 \mathrm{ppm}$ is due to the $-\mathrm{OCH}_{3}\left(\mathrm{C}_{17}\right)$ carbon of MMA. The signal for backbone methyl groups $\left(\mathrm{C}_{2}, \mathrm{C}_{14}\right)$ appear at $17.2 \mathrm{ppm}$. The resonance signals at 39.6 and $38.3 \mathrm{ppm}$ are due to backbone methylene groups, $\mathrm{C}_{1}$ and $\mathrm{C}_{13}$ respectively. The resonance signal at $18.39 \mathrm{ppm}$ is attributed to $\mathrm{C}_{3} \& \mathrm{C}_{15}$ carbons. The resonance signal at $27.46 \mathrm{ppm}$ is attributed to methyl carbon $\left(\mathrm{C}_{12}\right)$. The ketonic carbonyl $\left(\mathrm{C}_{11}\right)$ of MAP-MMA appeared at $196.82 \mathrm{ppm}$ as sharp intense signal. The ester carbonyl groups appear at $165.21\left(\mathrm{C}_{16}\right)$ and $164.52\left(C_{4}\right) \mathrm{ppm}$. The $\mathrm{C}_{5}$ of phenyl ring appeared at $135.54 \mathrm{ppm}$. The $\mathrm{C}_{6} \& \mathrm{C}_{9}, \mathrm{C}_{7} \& \mathrm{C}_{8}$ aromatic carbons gave sharp signals at 130.64 and $122.32 \mathrm{ppm}$. The signal observed at $154.68 \mathrm{ppm}$ is attributed to $\mathrm{C}_{10}$ of the phenyl ring.

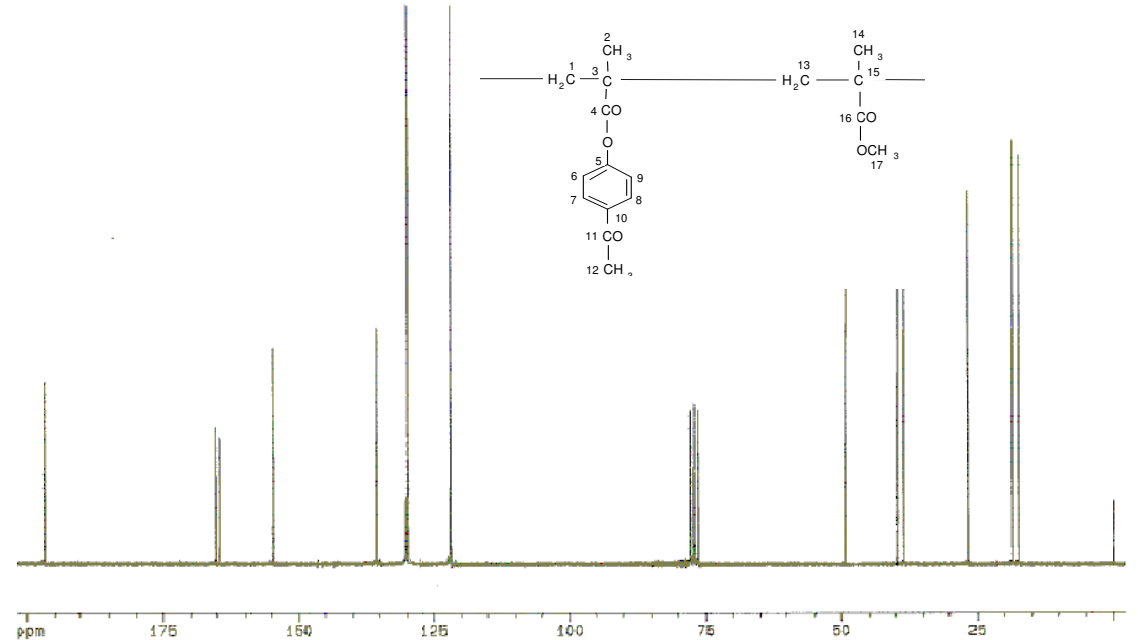

Figure 2. ${ }^{13} \mathrm{C}$ NMR spectrum of MAP-MMA copolymer

\section{Characterization of the functionalized copolymer}

\section{IR spectra}

The formation of hydrazone is confirmed by a set of distinct vibrations at 3426 and $1630 \mathrm{~cm}^{-1}$ which are due to $-\mathrm{NH}$ and $\mathrm{C}=\mathrm{N}$ stretching, respectively. The disappearance of the band at $1690 \mathrm{~cm}^{-1}$ indicates the removal of the surface ketonic carbonyls of the MAP units. The presence of another absorption band around $1700 \mathrm{~cm}^{-1}$ clearly indicates the intactness of ester carbonyl of acrylate units. This clearly indicates formation of hydrazone derivative.

\section{Thermogravimetric analysis}

To study the thermal stability and decomposition patterns of the cross-linked copolymers dynamic thermogravimetric analysis was undertaken. The thermograms of MAP-MMA copolymer and its isonicotinoyl hydrazone derivative were run in air. The thermograms are shown in Figure 3. The initial decomposition of MAP-MMA begins at $138{ }^{\circ} \mathrm{C}$. The degradation of MAP-MMA copolymer occurred in two stages. The first stage decomposition 
is observed from $176-372{ }^{\circ} \mathrm{C}$ and the weight loss is about $50 \%$. The second stage degradation of the copolymer resin is in the temperature range $372-530{ }^{\circ} \mathrm{C}$. The weight loss involved in this stage is $46.7 \%$. The decomposition of MAP-MMA-INH begins at $146{ }^{\circ} \mathrm{C}$. The isonicotinoyl hydrazone derivative also decomposed in a two-stage process. The first stage of decomposition commenced at $220{ }^{\circ} \mathrm{C}$ and completed at $413{ }^{\circ} \mathrm{C}$ with a weight loss of $72 \%$. The second stage decomposition is between 413 and $558^{\circ} \mathrm{C}$ and the weight loss is about $25.6 \%$.

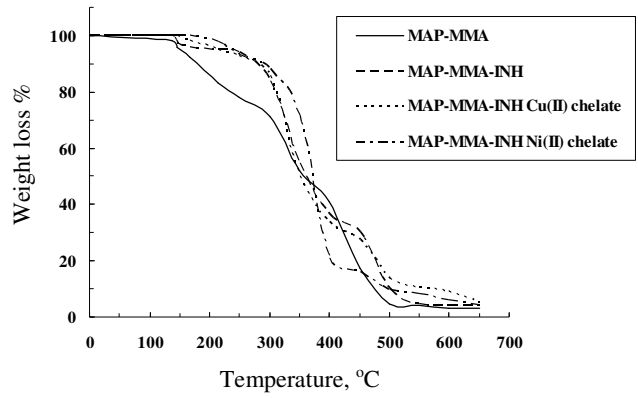

Figure 3. Thermograms

\section{Characterization of the metal complexes}

Elemental analysis

The metal chelates are coloured solids and insoluble in common organic solvents. The $\mathrm{C}, \mathrm{H}$ and $\mathrm{N}$ elemental values of the resin complex decreased when compared to the functionalized resin. The amount of the metal incorporated in the copolymer is determined by estimation the metal ions. Metallation was $20 \%$ and $23 \%$ for the $\mathrm{Cu}$ (II) and $\mathrm{Ni}$ (II) complexes respectively. Elemental analyses have shown that ligand (MAP-MMA-INH) to metal ratio is 2:1 in both the polychelates.

IR spectra

Comparison of the IR spectra of functionalized polymer and polychelates gives information regarding the nature of chelation. The presence or absence and shift of some bonds may be utilized to establish the nature of chelation. The IR spectra of functionalized copolymer shows intense band due to $\mathrm{C}=\mathrm{O}$ stretching at $1658 \mathrm{~cm}^{-1}$ and its downward shift to $1640 \mathrm{~cm}^{-1}$ in $\mathrm{Cu}(\mathrm{II})$ complex suggest coordination of metal ion through oxygen atoms. There is a downward shift of $\mathrm{C}=\mathrm{N}$ stretching band of azomethine group from $1630 \mathrm{~cm}^{-1}$ to $1595 \mathrm{~cm}^{-1}$ which indicates the coordination of azomethine nitrogen atom. This indicates the participation of the carbonyl groups (present in the hydrazone units) and $\mathrm{C}=\mathrm{N}$ groups in coordination with the metal ions ${ }^{16,17}$. Similarly in the case of the Ni(II) complex azomethine nitrogen and hydrazone carbonyl groups were involved in coordination. The $\mathrm{C}=\mathrm{O}$ and $\mathrm{C}=\mathrm{N}$ stretching frequency of $\mathrm{Ni}(\mathrm{II})$ complex are lower than those of the hydrazone and noticed at 1595 and $1520 \mathrm{~cm}^{-1}$ respectively. Thus, in each complex the metal atom binds to the ligand through azomethine nitrogen and hydrazone carbonyl oxygen atom.

\section{EPR spectroscopy}

The EPR spectrum of the MAP-MMA-INH Cu(II) complex is shown in Figure 4. The EPR parameters ( $g$ values) give a measure of the nature of the complexation with the metal ion. The EPR parameters calculated by Kneubuhl ${ }^{18}$ method for the copper complex is found to be $\mathrm{g}_{||}, 2.18 ; \mathrm{g}_{\perp}, 2.06$. For the covalent complexes, $\mathrm{g}_{||}$is less than 2.3 and for ionic environments it is normally 2.3 or larger $^{19}$. The $\mathrm{g}_{||}$values of the $\mathrm{Cu}$ (II) complex is 2.18 , indicating the covalent nature of the complex. 


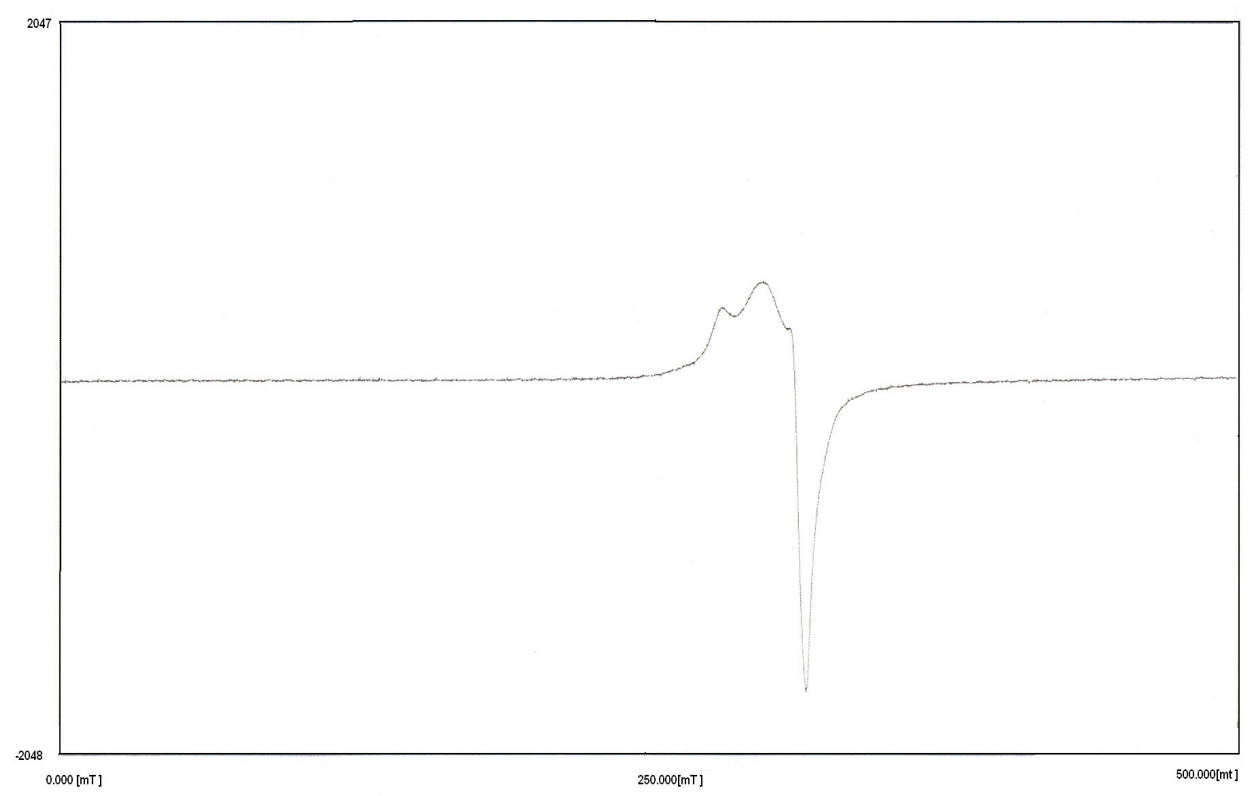

Figure 4. EPR spectrum of MAP-MMA-INH-Cu(II) chelate

\section{Thermogravimetric analysis}

The TGA curves of the polychelates are shown in Figure 3. The initial decomposition temperature (IDT) of the polychelates is higher than that of the copolymers and above $166{ }^{\circ} \mathrm{C}$. The degradation Copper chelate begins at $167{ }^{\circ} \mathrm{C}$ and that of Nickel chelate at $214{ }^{\circ} \mathrm{C}$. The degradation occurred mainly in two stages and decomposition is fast up to $400{ }^{\circ} \mathrm{C}$. The first stage decomposition may be due to the rupture of weak linkages and volatilization of low molecular weight fragments. The second slow decomposition of chelates at higher temperature may be due to the breakage of main chain accompanied by the volatilization of the cleaved products.

\section{Scanning electron microscopy}

Scanning electron microscopy has been employed for studying the shape, size and morphological features of the polymer. The micrograph of MAP-MMA is presented in Figure 5. It can be seen from the microphotograph that the copolymer particles are of varied shape and size. The functionalized polymer shows some amorphous nature when compared to copolymer indicating the success of functionalization. The surface of the polychelate has a rough appearance, indicating doping of the metal ions.

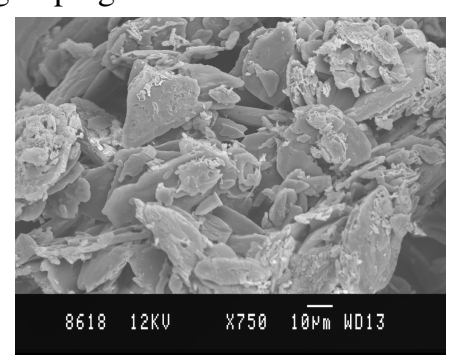

Figure 5. SEM microphotograph of MAP-MMA copolymer 


\section{Conclusion}

Poly 4-methacryloxyacetophenone-methyl methacrylate was prepared in ethyl methyl ketone using benzoyl peroxide as the initiator. The isonicotinoyl hydrazone ligand was attached to the keto functional group and the resulting ligand polymer used to prepare polymer-metal chelates. IR spectral studies showed the azomethine nitrogen and isonicotinoyl carbonyl group and chloride anions were involved in coordination to the metal ions, $\mathrm{Cu}$ (II) and $\mathrm{Ni}$ (II). Elemental analysis confirmed that the percentage of functionalization was 41 , while the metallation was 20 and 23 for $\mathrm{Cu}(\mathrm{II})$ and $\mathrm{Ni}(\mathrm{II})$ chelates, respectively. The EPR spectra of the $\mathrm{Cu}(\mathrm{II})$ complex showed that the metal-ligand bond is covalent in nature. Thermal studies were carried out and the thermal dissociation patterns discussed. SEM photographs indicate the success of polymerization.

\section{Acknowledgement}

The authors thank the University Grants Commission, New Delhi for financial support in the form of a Major Research Project. The authors also thank the Sophisticated Analytical Instruments Facilities at IISC, Bangalore and IICT, Hyderabad and Central University, Hyderabad, India for the elemental analysis, SEM, NMR and FTIR, TGA and EPR spectral studies, respectively.

\section{References}

1. Thamizharasi S and Rami Reddy A V, Poly., 1992, 33(11), 2421-2423.

2. Francisca Mary L J and Rami Reddy A V, Eur Poly J., 1991, 27(7), 627-631.

3. Rami Reddy AV, Sambasiva Reddy P and Reddy G H, Eur Poly J., 1999, 35(5), 965-971.

4. Pedersen C J and Frensdroff H K, Angewandt Chem Int Edn., 1972, 11(1), 16-25.

5. Rollman L D, J Am Chem Soc., 1975, 97, 4044-4051.

6. Drago R S, Gaul J, Zombeck A and Stamb D K, J Am Chem Soc., 1980, 102(3), 1033-1038.

7. Montegazza P, Panchiane F and Cavalind G, Antibiot Chemother., 1961, 11, 405-409.

8. Katyal M and Dutt J, Talanta, 1975, 22(2), 151-166.

9. Babaiah O, Rao C K, Reddy T S and Reddy V K, Talanta,, 1996, 43(4), 551-558.

10. Babaiah O, Reddy P R, Reddy V K and Reddy T S, Indian J Chem Sect A, 1999, 38, 1035; J Indian Chem Soc., 2004, 81, 670.

11. Gangadharappa M, Reddy PR, Reddy V K and Reddy T S, J Indian Chem Soc., 2004, 81, 525-527.

12. Reddy V K, Thippaiah J, Rao C K, Reddy P R and Reddy T S, J Indian Chem Soc., 1999, 76, 275.

13. Weiliao I and Etchinger B E, J Polym Sci.Part A Polym Chem., 1990, 28(3), 559-571.

14. Torikai A, Takeuchi A, Nagaya S and Fueki K, Polym Photochem., 1986, 7(3), 199-211.

15. Wendlandt W W, Thermal Methods of Analysis, Interscience Publications: New York, 1964.

16. Stone M E and Johnson K E, Canad J Chem., 1973, 51, 1260.

17. Tanaka H, Kuma H and Yamada S, Bull Chem Soc Jpn., 1977, 50, 3259.

18. Kneubuhl F K, J Chem Phys., 1960, 33, 1074.

19. Okawa H, Tokii T, Noraka N, Muto Y and Kida S, Bull Chem Soc Jpn., 1973, 46, 1462. 